\title{
COMPLEX PROCESSING OF POLYMETALLIC LEAD-ZINC ORE
}

\author{
I.G. Antropova ${ }^{a, b}$, A.Y. Dambayeva ${ }^{a, l}$ \\ abaikal Institute of Nature Management, Siberian Branch of Russian Academy of science, \\ Sakhyanova str., 6, Ulan-Ude 670047, Russia. \\ bEast - Siberian State Technological University, Klutshevskaya str., 40B, \\ Ulan-Ude 670013, Russia.
}

\begin{abstract}
It is known that oxide minerals of useful components are presented by complex oxidized forms and are not practically floatable. The paper gives the opportunity for complex oxide leadzinc ore to be prepared effectively to flotation beneficiation based on pyrosulphidization of oxide minerals while roasting. The process of roasting is held in the atmosphere of overheated steam using sub-quality pyrite concentrates as sulphidizer. Using such pyrite concentrates make it possible to solve the problem of utilization and treatment of pyrite concentrates.
\end{abstract}

Keywords: sulphidization roasting, pyrometallurgy, oxide ores, mineral processing, overheated steam

1 Corresponding author: Aida Dambayeva, address: Baikal institute of nature management SB RAS, 670047 Russia, tel.: +7 3012211392,e-mail address: aidadd@mail.ru

\section{Introduction}

Significant stocks of polymetallic ores are concentrated on the territory of East Siberia. The ores of most oxide and complex polymetallic ores in the deposits are complex and the ways of their treatment have not been developed yet. Minerals in such ores are presented by carbonates, sulphates, silicates, oxides and other mineral compounds possessing various floatability [1]. Meanwhile oxide ores represent a large raw source of extracting lead, zinc, copper and other nonferrous metals. In a world practice by treatment complex oxide ores of heavy nonferrous metals, there is a tendency of applying combined methods including operations of hydro- or pyrometallurgy in a combination with floatational or gravitational ore beneficiation, depending on peculiarities of ore composition. There are well-known ways of processing oxide lead and lead-zinc ores offered $[2,3]$ who provide for a preliminary sulphidizing roasting and flotation. As a sulphidizer, pyrite is used in the first case, and elementary sulfur in the second one. Those methods have disadvantages such as the necessary use of pure pyrite as a sulphidizer, as well as expensive elementary sulphur and rigid requirements to a temperature mode.

In this respect, one of the effective ways of translating oxygen-bearing minerals of heavy nonferrous metals in sulphide forms for the subsequent flotation is pyrosulphidization of complex oxide minerals in the atmosphere of overheated water steam. Sulphidizing roasting of oxide ores in the atmosphere of overheated steam provides decrepitating of complex minerals with their simultaneous dissociation, and then causes sulphidization of products of decomposition $[4,5,6]$. Sub-quality pyrite concentrates of local mining factories can be used as effective sulphidizer. The problem connected with their recycling and complex processing will be partially solved using pyrite concentrates as sulphidizer.

The present work shows the results of investigations on ore treatment of complex oxide lead-zinc ore using sulphidization roasting in the atmosphere of overheated water steam. 


\section{Experimental}

The object of experimental investigations was the oxidized ore sample of one of the deposits in Buryatia, of the composition in $\%: \mathrm{Pb}$ - 7,11; $\mathrm{Zn}$ - 4,16; Fe-32,0; $\mathrm{SiO}_{2}$ - 1,93; $\mathrm{MgO}$ - 4,95; $\mathrm{CaO}-12,02 ; \mathrm{Cu}-0,04 ; \mathrm{Mn}-8,02 ; \mathrm{S}$ - 3,45; $\mathrm{CO}_{2}-14,0$ and $\mathrm{Ag}-800 \mathrm{~g} / \mathrm{t}$. The phase composition of source materials and products of interactions was defined on the up-to-date Xray diffraction meter D8 ADVANCE of Bruker AXS firm. According to X-ray analysis (fig.1), the oxide lead minerals are presented basically by cerrussite $\left(\mathrm{PbCO}_{3}\right)$, while anglesite $\left(\mathrm{PbSO}_{4}\right)$ is less frequently found. The oxidized form of zinc is smithsonite with a large amount of iron $\left(\mathrm{ZnCO}_{3}\right)$. The basic ore mineral is magnetite $\left(\mathrm{Fe}_{3} \mathrm{O}_{4}\right)$. The ore mineral and substance composition being complex, effective components are zinc with cadmium accompanying it, lead with silver accompanying it and iron.

The main ore-forming mineral - magnetite content of which ranges from $40-90 \%$ of the ore bodies, it is advisable to an-annealing in a separate product of magnetic separation techniques.

Products of wet magnetic separation (magnetic and nonmagnetic fractions) were analyzed for lead, zinc, iron, sulfur and manganese.
The best technological parameters of the separation is achieved by grinding the ore-to $0.25 \mathrm{~mm}$ and the magnetic field $45 \mathrm{kA} / \mathrm{m}$

The output of the magnetic fraction is $59.82 \%$ when the content of the iron $-51.0 \%$, with recovery in a $95.3 \%$ iron, $7.6 \%$ lead and $13.8 \%$ zinc. Also in the magnetite concentrate passes $87.65 \%$ of manganese. The sulfur content in the iron product is $0.15 \%$, which is acceptable for iron concentrates (up to 0.15$0.2 \%$ ).

The study of the sulphidizing roasting process of the oxide lead-zinc ore in the atmosphere of overheated steam was conducted on the specially developed installation with the use of sub-quality pyrite concentrates with the content of sulfur of $38 \%$ as a sulphidizer. The installation consists of three basic units - a steam and gas generator, a reactor (the furnace of «a boiling layer") and a system of catching and clearing of gases. The installation works as follows - when a required temperature in the reactor and the steam generator is reached, the steam comes in the installation through an atomizer. Having washed all the system by the steam, the reactor is loaded by the required mass of batch. The design of the installation allows other gases to enter the reactor.

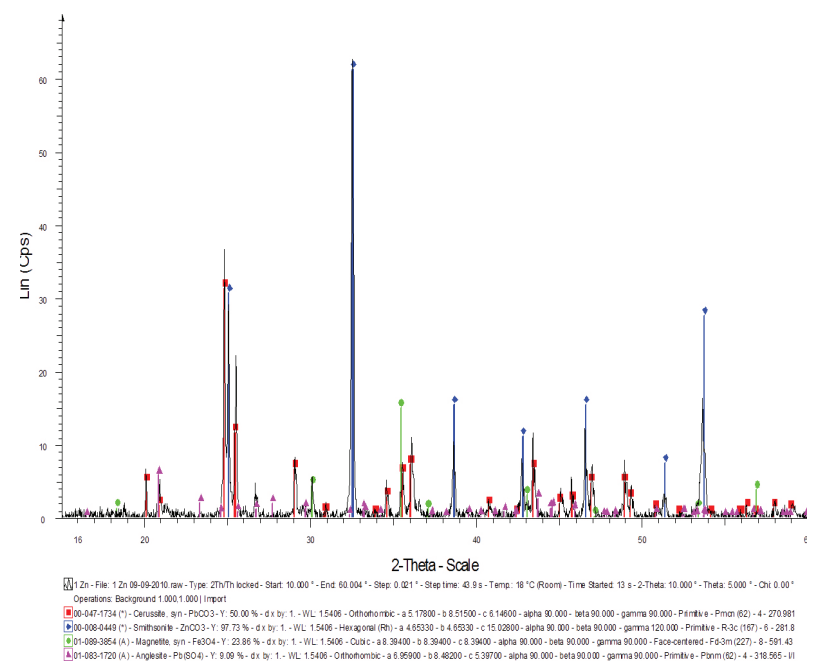

Fig. 1. The XRD pattern of original sample of oxidized ore 


\section{Results and discussion}

To define the optimum conditions of sulphidizing ore roasting in the steam atmosphere, a method of probabilistic-determinate planning of the experiment have been used [7]. Since an ultimate goal of the process is the transformation of low floatable oxide mineral forms into high floatable ones, the investigated functions were qualitative technological parameters such as the extraction of lead and zinc in concentrates. The experiments were carried out according to the conditions of the threefactor plan of the experiment at five levels, presented in tab. 1 .
The control of the roasted product for floatability was conducted by the method of collective flotation. The conditions of flotation were not changed. The products of flotation were analyzed on the content of basic components, the Y-ray phase analysis was selectively made. The following reagents were used in the collective flotation cycle of lead and zinc sulfides: butyl xanthate $100 \mathrm{~g} / \mathrm{t}$, soda $180 \mathrm{~g} / \mathrm{t}$, sodium sulphide $200 \mathrm{~g} / \mathrm{t}$, copper sulfate 150 $\mathrm{g} / \mathrm{t}$, liquid glass $80 \mathrm{~g} / \mathrm{t}$ and pine oil as a foam generator.

The obtained experimental data have been processed according to the methods [8].

Table 1

The levels of studied factors.

\begin{tabular}{|l|c|c|c|c|c|}
\hline \multirow{2}{*}{ Factor } & \multicolumn{5}{c|}{ Level } \\
\cline { 2 - 6 } & 1 & 2 & 3 & 4 & 5 \\
\hline $\mathrm{X}_{1}$, temperature, 0C & 400 & 500 & 600 & 700 & 800 \\
$\mathrm{X}_{2}$, duration, min.. & 10 & 20 & 30 & 40 & 50 \\
$\mathrm{X}_{3}$, sulphidizer consumption, g & 5 & 10 & 15 & 20 & 25 \\
\hline
\end{tabular}

The results of correlation factor calculations and its value have shown that all private dependences are significant (tab. 2).

Table 2

Correlation factor values and signification of private dependences.

\begin{tabular}{|c|c|c|}
\hline Equation & Coefficient correlation, $\mathrm{R}$ & Significance coefficient, $\mathrm{tr}$ \\
\hline $\mathrm{Y}_{1 \mathrm{~Pb}}=77.0-0.0003\left(\mathrm{X}_{1}-730\right)^{2}$ & 0.988 & $71.3>2$ \\
$\mathrm{Y}_{2 \mathrm{~Pb}}=64.4+0.079 \mathrm{X}_{2}$ & 0.826 & $4.5>2$ \\
$\mathrm{Y}_{3 \mathrm{~Pb}}=68.9-0.03\left(\mathrm{X}_{3}-20\right) 2$ & 0.982 & $47.6>2$ \\
$\mathrm{Y}_{1 \mathrm{Zn}}=66.0-0.0003\left(\mathrm{X}_{1}-760\right)^{2}$ & 0.870 & $10.7>2$ \\
$\mathrm{Y}_{2 \mathrm{Zn}}=53.6+0.057 \mathrm{X}_{2}$ & 0.799 & $3.8>2$ \\
$\mathrm{Y}_{3 \mathrm{Zn}}=45.7+0.636 \mathrm{X}_{3}$ & 0.812 & $7.2>2$ \\
\hline
\end{tabular}

The generalized multifactorial equations made of significant private dependences for function $\mathrm{Y}_{1}$ and $\mathrm{Y}_{2}$, are presented as follows:

$$
\begin{gathered}
Y_{1(\ddot{I})}=\frac{77,0-0,0003\left(\tilde{O}_{1}-730\right)^{2} \times\left(64,4+0,079 \tilde{O}_{2}\right) \times\left(68,9-0,03\left(\tilde{O}_{3}-20\right)^{2}\right)}{4422,25} \\
Y_{2(\ddot{I})}=\frac{66,0-0,0003\left(\tilde{O}_{1}-760\right)^{2} \times\left(53,6+0,057 \tilde{O}_{2}\right) \times\left(45,7+0,63 \tilde{O}_{3}\right)^{2}}{2948,49}
\end{gathered}
$$

The correlation factor of the generalized equation $\mathrm{Y}_{1 \text { (n) }}$ makes $\mathrm{R}=0,974$ for the value $t_{\mathrm{R}}$ $=89,2$ accordingly for $\mathrm{Y}_{2 \text { (n) }} \mathrm{R}=0,892$ for the value $t_{R}=20,0$. The error for the generalized equation $\mathrm{Y}_{1 \text { (r) }}$ was equal to 1,86 abs. $\%$, and for $\mathrm{Y}_{2 \text { (п) }}-6,05 \%$.

Analyzing the obtained data and generalized equations of the process, it is possible to draw a conclusion, is mostly influenced by the process of formation both of lead sul- 
fides and zinc sulfides the temperature of ore roasting process $\left(\mathrm{X}_{1}\right)$ and the amount of sulphidizer $\left(\mathrm{X}_{3}\right)$. The duration of roasting $\left(\mathrm{X}_{2}\right)$ least influences the process of sulphidization.

The obtained models of the sulphidizing ore roasting enable to define the optimum conditions of its realization for various combinations of operating factors. For example, at temperature of $650^{\circ} \mathrm{C}$, the duration of roasting of 30 minutes and the amount of pyrite concentrate used of 20 grams, the extraction of lead and zinc in a concentrate makes - 78,1 and $68,2 \%$ correspondingly.

The analysis of private dependences of lead and zinc extraction into a concentrate obtained from the investigated factors and technological reasons shows that optimum conditions of sulphidizing roasting process of the oxide lead-zinc ore of the magnitude of 1,0 $\mathrm{mm}$ are as follows: the temperature is $600-650$ ${ } \mathrm{C}$; the duration of roasting is $20-30$ minutes; the amount of sulphidizer used is $50 \%$ of extra content of sulfur concentrate from stoichiometry.

According to X-ray phase analysis of cinder at $600-800{ }_{\Theta C}$, the time of roasting of 30 minutes and a small extra amount of the pyrite concentrate used from stoichiometry, the end-products of interactions are galena $(\mathrm{PbS})$, sphalerite $(\mathrm{ZnS})$, wurtzite $(\mathrm{ZnS})$, magnetite $\left(\mathrm{Fe}_{3} \mathrm{O}_{4}\right)$ and pirrhotine $\left(\mathrm{Fe}_{1-\mathrm{x}} \mathrm{S}\right.$.). As a result of roasting with a pyrite concentrate in the steam atmosphere, smithsonite $\left(\mathrm{ZnCO}_{3}\right)$ is modified into sfalerite in $80 \%$ cases and into wurtzite in $20 \%$ cases correspondingly. The sulfides of lead and zinc being formed in the given system are still inert when rising up to $800 \mathrm{\Theta C}$.

A method of successive selective flotation of lead and zinc has been used to isolate sulfides of lead and zinc from the cinder obtained by sulphidizing ore roasting [9]. The best results of flotation separation have been obtained by grinding cinder up to $50 \%$ size class been equal to $0.074 \mathrm{~mm}$. The charge of reagents in the lead cycle was as follows: the regulator of medium was soda, $250 \mathrm{~g} / \mathrm{t}$; the collector was butyl xanthate, $35 \mathrm{~g} / \mathrm{t}$; foam generator was pine oil, $20 \mathrm{~g} / \mathrm{t}$. A combination of sulphurous sodium with sulphite sodium was used as a depressor. In the zinc flotation the activator was copper sulfate, $300 \mathrm{~g} / \mathrm{t}$; the collector was a combination (1:1) of butyl xanthate and aerofloat, $100 \mathrm{~g} / \mathrm{t}$; a regulator of medium was lime carbonate having $\mathrm{pH}$ up to 11 . Flotation was conducted according the scheme including the basic, control operation.

The developed conditions of roasting and flotation allowed to obtain a lead concentrate with the content of $42,9 \% \mathrm{~Pb}$ by extracting $\mathrm{Pb}$ of $89,8 \%$ and a zinc concentrate with the value of $36,5 \% \mathrm{Zn}$ and $4,03 \% \mathrm{~Pb}$ by extracting $\mathrm{Zn}$ of $70,7 \%$ (table 3 ).

Table 3

Technological parameters of cinder flotation by sulphidizing ore roasting in the steam atmosphere

\begin{tabular}{|l|c|c|c|c|c|c|c|c|c|c|c|}
\hline \multirow{2}{*}{ Product } & \multirow{2}{*}{$\gamma, \%$} & \multicolumn{4}{|c|}{ Containing $\beta, \%$} & \multicolumn{4}{c|}{ Extract $\varepsilon, \%$} \\
\cline { 3 - 12 } & & $\mathrm{Fe}$ & $\mathrm{Pb}$ & $\mathrm{Zn}$ & $\mathrm{Cd}$ & $\mathrm{Ag}, \mathrm{g} / \mathrm{t}$ & $\mathrm{Fe}$ & $\mathrm{Pb}$ & $\mathrm{Zn}$ & $\mathrm{Cd}$ & $\mathrm{Ag}$ \\
\hline Pb conc. & 29,33 & 0,75 & 42,93 & 1.28 & 0.004 & 757 & 3.13 & 89.82 & 3.32 & 1.92 & 90.1 \\
Zn conc. & 21,86 & 1,74 & 4,03 & 36,46 & 0.20 & 50 & 5.41 & 6.28 & 70.66 & 71.36 & 6.32 \\
Tailing & 48,81 & 13,15 & 1,12 & 6.01 & 0.03 & 33 & 91.44 & 3.90 & 26.02 & 26.72 & 3.58 \\
Cinder & 100 & 7,02 & 14,02 & 11.28 & 0.06 & 840 & 100 & 100 & 100 & 100 & 100 \\
\hline
\end{tabular}

The analysis of a gas phase by ore roasting has shown the presence of hydrogen sulphide and a small amount of sulphurous gas. The mechanism of sulphidization process of oxide compounds of lead and zinc can be assumed to be held as follows. A thermal dissociation of iron sulfide is known to be accompanied by separation of $\mathrm{S}^{0}$ :

$\mathrm{FeS}_{2} \rightarrow \mathrm{FeS}+\mathrm{S}$.

When iron sulfide interacts with water at temperature above $400{ }_{\theta} \mathrm{C}$, there is a reaction between elementary sulfur, the product of iron sulfide dissociation, and a steam with the separation of hydrogen sulphide and a sulphurous gas: 


$$
3 \mathrm{~S}+2 \mathrm{H}_{2} \mathrm{O}=2 \mathrm{H}_{2} \mathrm{~S}+\mathrm{SO}_{2}
$$

The interaction of sulphurous iron with the overheated steam is also accompanied by the separation of hydrogen sulphide.

$$
\mathrm{FeS}+\mathrm{H}_{2} \mathrm{O}=\mathrm{FeO}+\mathrm{H}_{2} \mathrm{~S}
$$

$\mathrm{FeO}$ forming in this case is being further oxidized and becomes Fe3O4. Therefore, by the interaction of iron sulfide with water the content of hydrogen sulphide prevails in the gas phase. Earlier thermodynamic calculations proved and experimentally confirmed sulphidization of lead and zinc carbonates which have composed up to oxides and lead sulphates by means of hydrogen sulphide.

$$
\begin{array}{r}
\mathrm{PbO}+\mathrm{H}_{2} \mathrm{~S}=\mathrm{PbS}+\mathrm{H}_{2} \mathrm{O} \\
\mathrm{ZnO}+\mathrm{H}_{2} \mathrm{~S}=\mathrm{ZnS}+\mathrm{H}_{2} \mathrm{O} \\
\mathrm{PbSO}_{4}+4 \mathrm{H}_{2} \mathrm{~S}=\mathrm{PbS}+\mathrm{nS}+4 \mathrm{H}_{2} \mathrm{O}
\end{array}
$$

\section{Conclusion}

The obtained data are the basis for the development of a new technology of processing oxide complex lead-zinc ores. This technology is based on the alteration of the mineralogical composition of valuable ore components according to flotation properties by means of sulphidizing oxide minerals during roasting in the atmosphere of overheated steam using sub quality pyrite concentrates as sulphidizer. This technology allows you to get along with lead and zinc concentrates a good raw material for steel industry - iron magnetite concentrate with a manganese content of $6-7 \%$.

\section{Acknowledgments}

The authors would like to thank the Russian Foundation for Basic Research for the financial support (№ 11-08-00691).

\section{References}

[1] A.A. Abramov The ways of improvement of concentration technology and processing of oxide and mixed ores, Moscow, Nauka, 1985, p.5-15.

[2] V.A. Chanturiya, E.A. Trofimova Processing of oxide ores. Moscow, Nauka. 1985, p.69-71.

[3] Li Yong, Wang Ji-kun, Wei Chang, Liu Chun-Xia, Jiang Ji-Bo, Wang Fan, Sulphidation roasting of low grade lead-zinc oxide ore with elementary sulfur. Minerals engineering, 23(2010) p.563566.

[4] A.N. Gulyashinov, I.G. Antropova, K.A. Nikiforov, A way of processing of oxidized lead ore, Patent of the Russian Federation, № 2179596, Appl. 21 99118158/02, Published 2.02.2002

[5] A.N. Gulyashinov, I.G. Antropova, K.A. Nikiforov, A way of processing of oxidized zinc ore, Patent of the Russian Federation № 2208059, Appl. 21 2001131339/02, Published 10.07.2003.

[6] I.G. Antropova, A.N. Gulyashinov, V.A. Lamuev, P.L. Paleyev, A way of processing of complex oxidized leads ore, Patent of the Russian Federation № 2364639, published 20.08.2009.

[7] V.P. Malyshev, Mathematical planning of the metallurgical and chemical experiment, AlmaAta, Nauka, 1977, p.36.

[8] M.M. Protodyakonov, R.I. Teder, Methods of rational planning the experiment, Moscow, Nauka, 1970, p.76.

[9] A.A. Abramov, Theoretical principles of selective flotation optimization of sulphide ores, Moscow, Nedra, 1978. 